\title{
ANÁLISE DE VERBETES EM DICIONÁRIOS ESCOLARES DO TIPO 3 DO PROGRAMA NACIONAL DO LIVRO DIDÁTICO
}

\author{
Maria Laura da Silva* \\ Márcio Sales Santiago
}

\begin{abstract}
RESUMO: 0 dicionário escolar é um importante instrumento de ensino/aprendizagem de língua materna, entretanto, pouco utilizado em sala de aula, haja vista que muitos professores não possuem o domínio das múltiplas funções que o dicionário pode alcançar ao ser explorado nas suas diversas especificidades. Nessa perspectiva, este trabalho objetivou analisar verbetes que figuram nos dicionários escolares do tipo 3 , avaliados e selecionados pelo Programa Nacional do Livro Didático (PNLD - Dicionários 2012), do Ministério da Educação (MEC). Estes dicionários escolares são destinados para os alunos do sexto ao nono ano do ensino fundamental II. Em face disso, observamos as várias possibilidades pedagógicas do uso do dicionário em sala de aula por meio da análise contrastiva dos verbetes. Tomamos como pressuposto teórico da Lexicografia Pedagógica os trabalhos de Krieger (2007; 2012), Pontes (2009) e Santiago (2012, 2015). 0 corpus foi constituído por cinco dicionários do tipo 3 aprovados pelo PNLD Dicionários 2012, nos quais foram selecionados verbetes a partir de alguns critérios pertinentes. Os dados relativos aos verbetes foram registrados em fichas criadas em um banco de dados com a finalidade de armazenar as informações de cada verbete. As análises revelaram aspectos paradigmais divergentes de um mesmo verbete em diferentes dicionários, bem como informações que são comuns entre os dicionários analisados.
\end{abstract}

PALAVRAS-CHAVE: Lexicografia pedagógica; Dicionário escolar; PNLD.

\section{ANALYSIS OF TERMS IN TYPE 3 SCHOOL DICTIONARIES IN THE NATIONAL DIDACTIC BOOK PROGRAM}

\begin{abstract}
The school dictionary is a highly relevant tool for teaching/learning of the mother tongue, even though it is scarcely employed in the classroom. This is due to the fact that several teachers lack dominion on its multiple functions and specificities. Current analysis studies terms in Type 3 school dictionaries, evaluated and selected by the National Didactic Book Program (PNLD - Dictionaries 2012) of the Brazilian Ministry of Education (MEC). The above mentioned dictionaries are used by 6 and 9 Year students of Basic Education. The several pedagogical possibilities for the use of the dictionary in the classroom are investigated by the contrastive analysis of the terms. Research by Krieger $(2007 ; 2012)$, Pontes $(2009)$ and Santiago $(2012,2015)$ foregrounds the theoretical presuppositions of the Pedagogical Lexicography. Research corpus comprised five Type 3 Dictionaries approved by the PNLD Dictionaries 2012, from which terms were selected. Data related to the terms were registered in charts established in a data base to store information on each term. Analyses reveal divergent and also common paradigmatic aspects of the same term in several dictionaries.
\end{abstract}

KEYWORDS: Pedagogical lexicography; School dictionary; PNLD.

\footnotetext{
Licenciada em Letras (Língua Portuguesa e suas Literaturas), pela Universidade Federal do Rio Grande do Norte (UFRN). Mestranda no Programa de Pós- Graduação em Estudos da Linguagem (PPGEL) da Universidade Federal do Rio Grande do Norte (UFRN). Bolsista de Iniciação Científica do CNPq de 2016 a 2018 no projeto "Lexicografia Pedagógica aplicada ao ensino de Língua Portuguesa: perspectivas para a formação docente". Brasil.

** Doutor em Letras/Estudos da Linguagem pela Universidade Federal do Rio Grande do Sul (UFRGS). Docente Adjunto da Universidade Federal do Rio Grande do Norte (UFRN), atuando no Departamento de Letras do Centro de Ensino Superior do Seridó (CERES) e no Programa de Mestrado Profissional em Letras (PROFLETRAS). Brasil. E-mail: msantiago@ceres.ufrn.br
} 


\section{INTRODUÇÃo}

A Lexicografia é a ciência que estuda a organização e elaboração dos dicionários. Apesar de ser considerada uma disciplina nova no campo da Linguística Aplicada, ela atua de forma significativa no estudo de como se constituem e para quem são destinados os dicionários.

Por seu valor linguístico, histórico e social, 0 dicionário se constitui como patrimônio de uma sociedade. A reflexão da complexidade que circunda a capacidade humana em recriar a linguagem é registrada nesse poderoso instrumento de comunicação. Tomando como base 0 dicionário escolar, temos um importante instrumento didático nas aulas de língua portuguesa, visto que seus registros vinculam informações que ultrapassam 0 simples papel de agregar significados às palavras.

Como uma política que visa ao melhoramento da educação pública brasileira, o Programa Nacional do Livro Didático (PNLD), do Ministério da Educação (MEC), passou a reconhecer o seu valor pedagógico. Entretanto, apesar da sua valorização, muitos professores não possuem formação para utilizar 0 dicionário de forma proveitosa, logo, os alunos não aprendem a como utilizá-lo. É o que Santiago (2015, p. 71) denomina de "danoso efeito dominó lexicográfico: 0 aluno não sabe usar o dicionário porque o professor não aprendeu como ensiná-lo a usar". Tal problema ocorre uma vez que os cursos de letras não possuem uma disciplina específica de capacitação dos profissionais, que diz respeito à Lexicografia, especialmente a Lexicografia Pedagógica, responsável por estudar de forma científica os dicionários escolares.

Em face da importância de um melhor aproveitamento do dicionário escolar, e tendo em conta que os dicionários são distribuídos pelo PNLD às escolas públicas, cujo acervo precisa ser trabalhado adequadamente, propomos neste trabalho analisar, por meio de análises contrastivas, os verbetes dos dicionários do tipo 3 , selecionados para alunos do sexto ao nono ano do ensino fundamental II, observando as possibilidades pedagógicas que podem contribuir para a formação docente e, em consequência, para melhor desempenho linguístico do aluno. Nessa perspectiva, adotamos como pressuposto teórico os estudos de Krieger $(2007,2012)$, Pontes (2009) e Santiago (2012, 2015) acerca da Lexicografia Pedagógica.

Neste artigo, visamos a oferecer contribuições para as práticas de ensino de língua portuguesa, proporcionando a professores em formação maiores possibilidades de utilização do dicionário em sala de aula, despertando 0 olhar crítico em relação à constituição da obra, bem como ressaltando a importância da Lexicografia Pedagógica, sem que haja um olhar tendencioso para nenhumas das obras selecionadas ${ }^{3}$.

\section{ASPECTOS TEÓRICOS: A LEXICOGRAFIA PEDAGÓGICA, 0 DICIONÁRIO ESCOLAR E O PNLD}

Para entender 0 objeto de nosso estudo, é necessário abordarmos os pressupostos da Lexicografia Pedagógica, disciplina responsável pelo estudo e organização dos dicionários escolares. Nesse sentido, utilizamos, na maior parte do nosso trabalho, os pressupostos de especialistas que atuam nessa área.

A partir de 2001, por meio do PNLD, os dicionários passaram a ser avaliados por uma comissão de especialistas na área de Lexicografia, entretanto, foi em 2006 que ocorreram grandes mudanças nas diretrizes de avaliação das obras lexicográficas destinadas às escolas. Tais mudanças dizem respeito, respectivamente, à criação de obras direcionadas especialmente para 0 uso escolar; à criação de tipologias relacionadas ao nível de aprendizagem do aluno e à elaboração por parte do MEC de manuais para orientação do professor e explicitação da proposta lexicográfica ${ }^{4}$.

\footnotetext{
Essas contribuições são oriundas de resultados alcançados pelo projeto de pesquisa intitulado "Lexicografia Pedagógica aplicada ao ensino de língua portuguesa: perspectivas para a formação docente".

4 Alguns desses manuais podem ser encontrados na página do PNLD destinada aos dicionários, por meio do endereço: http://portal.mec.gov. $\mathrm{br} / \mathrm{pn} / \mathrm{d} /$ dicionarios.
} 
$\mathrm{Na}$ última edição do PNLD Dicionários, ocorrida em 2012, as obras foram classificadas como pertencentes a quatro tipos:

- tipo 1: para $01^{0}$ ano do ensino fundamental;

- tipo 2: para o período entre $02^{\circ}$ e $05^{\circ}$ ano do ensino fundamental;

- tipo 3: para o período entre $06^{\circ}$ e $09^{\circ}$ ano do ensino fundamental;

- tipo 4: para o ensino médio.

Vale destacar que essa tipologia adéqua os dicionários escolares à proposta lexicográfica do aluno, segundo o PNLD 2012, conforme podemos observar no Quadro 1:

Quadro 1: Tipos de dicionários para o PNLD 2012

\begin{tabular}{|c|c|c|}
\hline $\begin{array}{l}\text { Tipos de } \\
\text { dicionários }\end{array}$ & $\begin{array}{c}\text { Etapa de } \\
\text { ensino }\end{array}$ & Caracterização \\
\hline $\begin{array}{l}\text { Dicionários } \\
\text { de tipo } 1\end{array}$ & $\begin{array}{c}1^{0} \text { ano do } \\
\text { ensino } \\
\text { fundamental }\end{array}$ & $\begin{array}{l}\text { - Mínimo de } 500 \text { e máximo de } \\
1.000 \text { verbetes; } \\
\text { - Proposta lexicográfica ade- } \\
\text { quada às demandas do pro- } \\
\text { cesso de alfabetização inicial. }\end{array}$ \\
\hline $\begin{array}{l}\text { Dicionários } \\
\text { de tipo } 2\end{array}$ & $\begin{array}{l}2^{0} \text { ao } 5^{\circ} \text { ano } \\
\text { do ensino } \\
\text { fundamental }\end{array}$ & $\begin{array}{l}\text { - Mínimo de } 3.000 \text { e máximo de } \\
15.000 \text { verbetes; } \\
\text { - Proposta lexicográfica ade- } \\
\text { quada a alunos em fase de } \\
\text { consolidação do domínio tanto } \\
\text { da escrita quanto da organiza- } \\
\text { ção e da linguagem típicas do } \\
\text { gênero dicionário. }\end{array}$ \\
\hline $\begin{array}{l}\text { Dicionários } \\
\text { de tipo } 3\end{array}$ & $\begin{array}{l}6^{0} \text { ao } 9^{\circ} \text { ano } \\
\text { do ensino } \\
\text { fundamental }\end{array}$ & $\begin{array}{l}\text { - Mínimo de } 19.000 \text { e máximo de } \\
35.000 \text { verbetes; } \\
\text { - Proposta lexicográfica orienta- } \\
\text { da pelas características de um } \\
\text { dicionário padrão de uso esco- } \\
\text { lar, porém adequada a alunos } \\
\text { dos últimos anos do ensino } \\
\text { fundamental. }\end{array}$ \\
\hline $\begin{array}{l}\text { Dicionários } \\
\text { de tipo } 4\end{array}$ & $\begin{array}{c}1^{0} \text { ao } 3^{\circ} \text { ano } \\
\text { do ensino } \\
\text { médio }\end{array}$ & $\begin{array}{l}\text { - Mínimo de } 40.000 \text { e máximo de } \\
100.000 \text { verbetes; } \\
\text { - } \quad \text { Proposta lexicográfica própria } \\
\text { de um dicionário padrão, po- } \\
\text { rém adequada às demandas } \\
\text { escolares do ensino médio, in- } \\
\text { clusive o profissionalizante. }\end{array}$ \\
\hline
\end{tabular}

Fonte: Brasil (2012, p. 19)
Nessa perspectiva, a utilização da Lexicografia Pedagógica é indispensável para a realização do nosso trabalho, pois está diretamente relacionada ao público escolar, que deve ter acesso ao dicionário escolar como ferramenta de aquisição da língua materna. Assim, de acordo com Krieger (2007, p. 247),

A concepção de uma Lexicografia
didática ou pedagógica, como uma
produção direcionada à escola é de
extrema importância sobretudo porque
há uma tendência geral de identificar
como escolar os dicionários tipo mini.
No entanto, a compreensão do caráter
escolar costuma estar associada mais
às suas dimensões reduzidas do que
à sua efetiva adequação ao ensino/
aprendizagem da língua.

Por conseguinte, é em relação a essa adequação que nos aprofundamos nesse trabalho, haja vista que, segundo Krieger (2012, p. 20),

Os dicionários destinados à escola, em particular os do tipo 3, conforme a terminologia do MEC, são inspirados na proposta de se construir ao modo de um dicionário padrão, fazendo 0 registro de um conjunto de léxico representativo de língua portuguesa, e sistematizando muitos dados sobre cada uma das palavras registradas. Em razão da sua funcionalidade na escola, esses dicionários trazem ainda informações sobre silabação, acentuação, relações de sinonímia, antonímia, famílias de palavras, entre outros aspectos, mais adiante detalhados.

Como se percebe, o dicionário, para além de ser um simples livro de consultas, é uma obra pedagógica e de representação cultural de uma determinada comunidade (SANTIAG0, 2012). Dessa forma, deve ser encarado como um rico instrumento de informações sobre a língua, que utilizado de forma estratégica pode ser um grande aliado durante as aulas, considerando que é um material acessível nas escolas.

Nesse sentido, o poder pedagógico do dicionário 
é imprescindível às aulas de língua portuguesa. Segundo Auroux (1992, p. 65), "0 dicionário (ao lado da gramática), como tecnologia, descreve e instrumentaliza uma língua e, ainda hoje, é considerado um dos pilares de nosso saber metalinguístico". Dessa forma, Pontes (2009, p. 25) ensina que

[...] 0 didatismo do dicionário faz com que este seja um instrumento pedagógico da maior importância, desde que cumpra convenientemente suas funções, entre tantas, a de auxiliar 0 aluno no desenvolvimento de habilidades de leitura, escrita e comunicação oral.

Por isso, é importante observar se os dicionários cumprem o didatismo necessário para que os alunos possam alcançar essas habilidades, levando em conta que este valor pedagógico é uma das funções do dicionário escolar, ou seja, atender as necessidades dos estudantes.

\section{ASPECTOS METODOLÓGICOS}

0 corpus da pesquisa é constituído pelo acervo composto dos dicionários escolares de língua portuguesa do tipo 3, que contemplam o mínimo de 19.000 e 0 máximo de 35.000 verbetes, os quais foram selecionados pelo PNLD Dicionários 2012 e distribuídos para as escolas públicas do sexto ao nono ano do ensino fundamental II de todo o país.

As obras selecionadas, que correspondem à tipologia adequada a esse nível de escolaridade, são: Dicionário escolar da Academia Brasileira de Letras (BECHARA, 2011), Aurélio Júnior: dicionário escolar da língua portuguesa (FERREIRA, 2011), Caldas Aulete: minidicionário contemporâneo da língua portuguesa (GEIGER, 2011), Dicionário didático de língua portuguesa (RAMOS, 2011) e o Saraiva jovem: dicionário da língua portuguesa ilustrado (SARAIVA; OLIVEIRA, 2010) ${ }^{5}$.

No tocante à estrutura, a grande maioria dos

\footnotetext{
5 Neste trabalho, representamos os dicionários respectivamente pelas seguintes siglas: DEABL, AJ, CA, DDLP e SJ.
}

dicionários selecionados organiza-se em ordem alfabética e descreve, conforme Santiago (2012, p. 2), "informações gramaticais, semânticas e pragmáticas, conhecimentos culturais referentes à língua em que ele está inserido através das unidades lexicais que 0 compõem".

Para tanto, a seleção dos verbetes foi feita a partir dos seguintes campos temáticos: ideologia, política, cultura, animais, frutas, ensino, ética, tabuísmo, baixo calão, dentre outros. Até 0 momento, foram analisados contrastivamente mais 40 verbetes, respectivamente de cada dicionário citado anteriormente. Isso equivale a cerca de 200 acepções estudadas, considerando que alguns dicionários não possuem todos os verbetes e/ou acepções selecionadas. Entretanto, para a exposição da nossa investigação, consideramos importante nos determos apenas a três campos temáticos, haja vista os vários aspectos encontrados.

Pelas limitações impostas pela metodologia da pesquisa lexicográfica, quais sejam um universo de mais de 100.000 verbetes, as análises são realizadas por amostragem, considerando a seleção dos verbetes, cuja escolha se dá por meio de listas de verificação que incluem palavras de diversos campos temáticos. Esta é a metodologia adotada ao se realizar análises e avaliações de dicionários, já que dada a extensão do corpus e a limitação de tempo e espaço é inviável investigar cada um dos verbetes.

Em vista disso, visando à análise dos verbetes, foi construída uma base de dados no programa Microsoft Access, a qual é composta por fichas lexicográficas criadas especialmente com a finalidade de compilar informações sobre os verbetes e contrastá-las de acordo com critérios da Lexicografia Pedagógica.

Os dados sobre os verbetes foram organizados em campos que serão relacionados e explicados na Figura 1, a fim de evidenciar a ficha lexicográfica como um resultado metodológico da pesquisa. 
UNIVERSIDADE FEDERAL DO RIO GRANDE DO NORTE

CENTRO DE ENSINO SUPERIOR DO SERIDO / DEPARTAMENTO DE LETRAS - CERES

PROJETO DE PESQUISA

Lexicografia Pedagógica aplicada ao ensino de Lingua Portuguesa: perspectivas para a formação docente

Pesquisador: Prof. Dr. Márcio Sales Santiago - Bolsista: Maria Laura da Silva

\section{- REGISTRO}

Responsável pela inserção Maria Laura da Silva $\vee$

Responsável pela revisão Márcio Sales Santiago $v$

Data de registro $28 / 04 / 2017$

\begin{tabular}{l|l|l|}
\hline & Imprimir \\
$\square$ & Revisar \\
\hline
\end{tabular}

DADOS MICROESTRUTURAIS

\section{PALAVRA-ENTRADA CRIOULO}

[Transcrição das Definições (1) [DEABL]

(2) Aurélio Júnio [AN]

(3)

Caldas Aulet [CA]

Dicionário Didático de LP [DDLPa
[DLCo

(5)
Saraiva Jovem [SJ]

(cri:ou.lo) adj. 1. Aplicava-se antigamente a pessoa de raça branca, nascida nas colônias europeias do ultramar, principalmente da América. 2. A plica-se também a negros nascidos no Brasil. 3. Que é nativo de certa região, em oposição ao que vem do exterior: cavalo crioulo; cana crioula. S.m. 4.indivíduo descendente de europeus, nascido numa das colônias de ultramar, especialmente na América. 5. Negro nascido no Brasil, por oposição ao originário da África. 6. (Ling) Cada uma v

Cri.ou.lo adj. 1. Dizia-se de indivíduo negro nascido na América. 2. Referente aos nativos de determinada região. 3. Relativo a crioulo (5) subst,masc. 4. Indivíduo crioulo. 5. linguagem Qualquer lingua que resulta do contato entre grupos que falam linguas distintas, e que mistura elementos delas, passando a ser a lingua materna de uma população.

(cri:ou.lo) a.s.m. 1 Pej. Que ou quem é negro. [At! Considerado depreciativo ou preconceituoso nesta acepção.] 2 Dizia-se antigamente de pessoa negra nascida

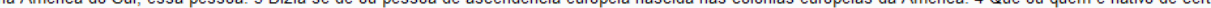
região. Sm. 5 Gloss. Cada uma das línguas essencialmente orais nascidas da mistura da língua europeia colonizadora com a lingua nativa: No Haiti fala-se crioulo

<cri ou lo la la adj. / s. 1 Que ou quem é negro e nascido no continente americano. 2 Em relação a uma língua, que é formada por elementos de línguas diferentes e que surgiu pela convivência de duas ou mais comunidades distintas.

(cri.ou.lo) adj e sm 1. Que ou quem é de etnia negra (O jogador crioulo saiu de Cabo Verde e atua no futebol de Portugal. "O recém chegado era um criolo alto, magro, de boa cara e de jeitos e meneios que revelam extrema benevolência". O Cabeleira Franklinizada Távora) 2 ant dizia-se de ou pessoa negra escravizad que nasceu na América do Sul; 3 Que ou quem é originário de determinada região (comida crioula, crioulo das pampas): sm 4 . Cada uma das línguas resuntantes

Anális

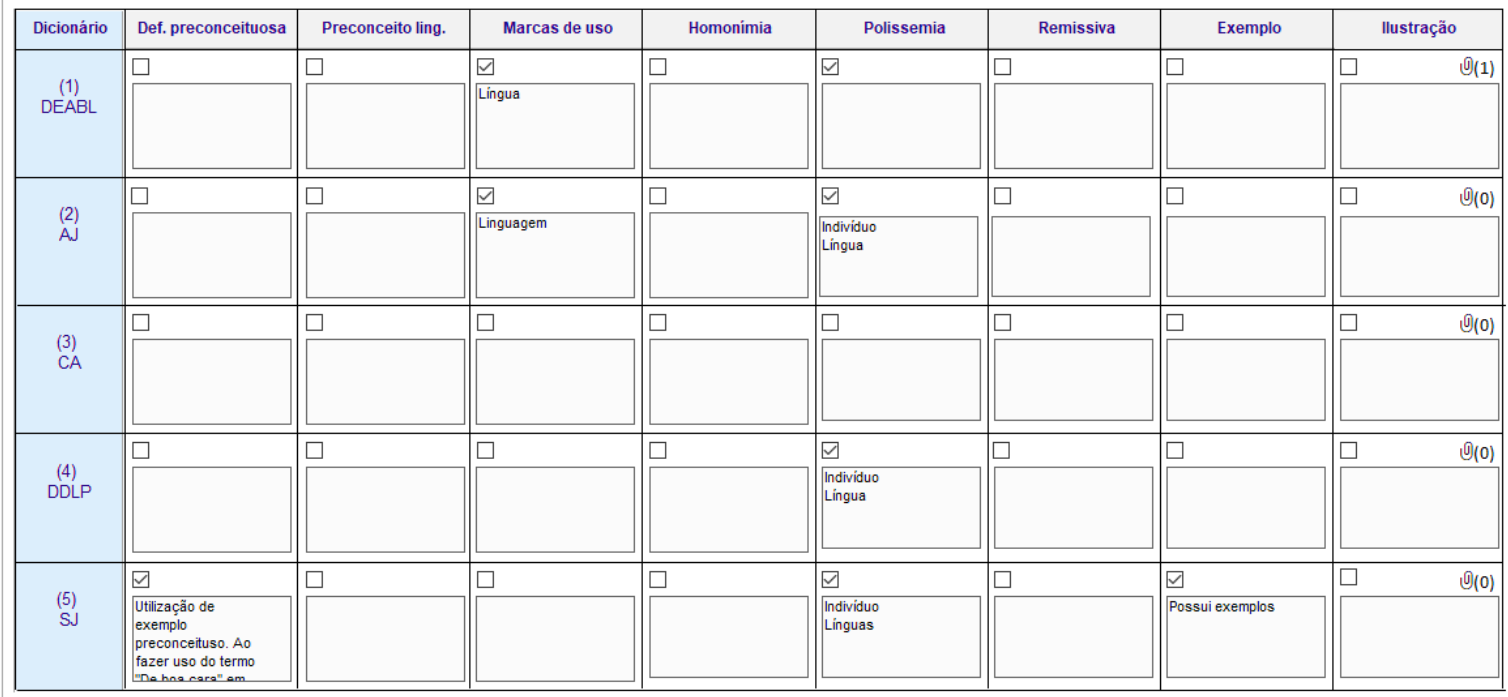

Observaçõe

Observaçôes

Comunicação

- Pesquisador $>$ bolsista

- Bolsista > pesquisador

MENU

Lista de Mensagens Mensagens

Figura 1: Ficha de análise do verbete Fonte: Elaborado pelos autores 
Como se pode observar, a ficha está dividida em três blocos principais: registro, dados microestruturais e análise. No cabeçalho contém as informações relativas à universidade, à agência que financia a pesquisa, ao título do projeto e aos nomes dos participantes.

Logo abaixo do cabeçalho, o primeiro bloco, denominado registro, refere-se aos dados de gestão da ficha. Nessa parte da ficha encontram-se as informações sobre quem e quando os dados foram registrados. No campo "Responsável pela inserção", é possível selecionar, em uma lista suspensa, os nomes do pesquisador e da bolsista envolvidos na pesquisa. A cada novo registro, marca-se o campo "Revisar" para que o pesquisador "Responsável pela revisão" possa fazer a verificação das informações adicionadas e confirmar, ou não, se a unidade candidata é um termo válido e representativo da área temática em questão. Ao lado, verifica-se o campo "Código". Esse campo serve para organizar e ordenar de forma sequencial cada entrada no banco de dados da pesquisa. Com isso, facilita-se a localização futura dos registros.

Passando-se às informações relativas aos dados microestruturais, isto é, sobre 0 verbete, 0 primeiro campo é o de registro da palavra-entrada. Abaixo, os paradigmas são relativos às transcrições das definições desta palavra nos cinco dicionários escolares do tipo 3 que compõem o corpus.

0 bloco seguinte é destinado às análises que seguem os seguintes critérios: definições preconceituosas, homonímia, antonímia, marcas de uso, remissiva, exemplo e qualidade da ilustração. Há um campo reservado para observações de natureza linguística ou enciclopédica sobre 0 verbete em exame. Existe, ainda, um campo de comunicação entre pesquisador e bolsista.

Ressaltamos que esse modelo de ficha, resultado dos estudos sobre a pertinência de cada informação, poderá ser alterado, conforme necessidade da pesquisa em andamento.

\section{ANÁLISE DOS VERBETES}

Antes de adentramos nas análises, cumpre mencionar que cada dicionário possui características próprias no que diz respeito à sua organização. Neste estudo, detemo-nos à análise das características dos paradigmas que compõem os verbetes dos dicionários selecionados. Convém salientar que os verbetes foram transcritos da forma como estão nos dicionários escolares analisados.

A fim de ilustrar a análise que fora empreendida, apresentamos o verbete pitomba nos cinco dicionários que compõem o corpus da pesquisa:

- $\quad$ DEABL - (pi.tom.ba) s.f. Pequena fruta agridoce, de cheiro agradável, fruto da pitombeira.

- $\quad$ AJ - pi.tom.ba subst. fem. 1. 0 fruto da pitombeira. 2. Gíria Tapa, bofetada. 3. Esportes chute forte.

- CA - (pi.tom.ba) sf. Bras. 1 pequena fruta ácida e de casca dura. 2 ver cascudo. [F.: Do tupi.]

- DDLP - <pi.tom.ba> s.f 1. Árvore com folhas oblongas ou lanceoladas, flores pequenas, e cujo fruto é uma baga carnosa e comestível. SIN. Pitombeira. 2. Esse fruto. ORIGEM É uma palavra de origem tupi.

- SJ - (pi.tom.ba) sf. 1. Bras. Bot. Árvore de grande copa, casca lisa e flores brancas, que formam cachos e frutos comestíveis redondos, de casca dura e sabor agridoce (A pitomba também é conhecida como pitombeira.); 2 . 0 fruto dessa árvore; 3. Gír. pancada, bofetada, cascudo (0 valentão encheu de pitombas 0 pobre coitado que aceitara o desafio de lutar com ele.).

Observamos que todos os dicionários selecionados trazem a separação silábica da palavra, bem como a classe gramatical (substantivo feminino) de acordo com a organização de cada um. 0 DEABL traz apenas uma acepção para 0 verbete analisado, 
classificando de forma objetiva que se trata de uma fruta, entretanto, se considerarmos as pessoas que nunca viram a fruta, a descrição não é considerada clara, haja vista que outras frutas podem possuir as mesmas características apresentadas por essa acepção.

Em relação ao AJ, o verbete possui três acepções: a primeira, também sucinta, revela 0 significado característico, qual seja uma fruta pertencente à pitombeira; a segunda possui marca de uso gíria, que a considera a palavra como significado de tapa ou bofetada; e na terceira, pitomba é uma palavra utilizada em esportes, como mostrado pela marca de uso, relacionada a chute forte. Nessa perspectiva, ao encontrarmos no AJ três acepções distintas para pitomba, classificamos o verbete como polissêmico.

Assim, segundo Krieger (2012, p. 52),

Ao falarmos de polissemia, referimos relações semânticas entre as palavras. São alargamentos de sentido, aproximações e contiguidades, como ocorre com a metáfora, a metonímia e a sinonímia. 0 resultado será um novo significado ou uma nova acepção, de acordo com a terminologia da Lexicografia. 0 registro dos diferentes sentidos de uma mesma palavra compõe a rede de acepções do verbete de entrada polissêmica.

$\mathrm{Na}$ microestrutura do dicionário $\mathrm{CA}$, temos duas acepções: a primeira possui a marca de uso "Bras." relativo à palavra constituinte de determinado lugar, isto é, do Brasil, o significado traz uma ideia aproximada da fruta pitomba; a segunda acepção apresenta uma remissiva, isto é, indicação para que o leitor procure a palavra cascudo para complementar o significado de pitomba. Consideramos que essa informação poderia vir relacionada com a primeira acepção. Há também uma indicação de que a palavra tem origem do Tupi.

Já o DDLP organiza duas acepções, a primeira concebe pitomba como árvore de folhas oblongas ou lanceoladas, que de certo modo, apresenta uma linguagem especializada, haja vista que, teoricamente, alunos de sexto ao nono ano sentem a necessidade de pesquisar o significado também dessas palavras. A pitomba também é marcada como sinônimo de pitombeira pela abreviatura "SIN", contudo, como diz Krieger (2012), é importante que os professores esclareçam que a sinonímia não representa um sentido semântico idêntico entre as palavras, e isso é de extrema importância para que os alunos possam construir seus textos ponderando essas equivalências. Na segunda acepção, remete como sendo o fruto da pitombeira, deixando evidente que o sentido principal de pitomba trata-se de árvore. Por fim, há uma indicação sobre a origem da palavra, que vem do Tupi.

0 SJ apresenta três acepções: a primeira, que a define como árvore, traz duas mascas de uso, que dizem respeito à diatopia e à indicação da área científica, no caso, a botânica. A segunda acepção retrata a palavra como 0 fruto dessa árvore, sem que haja características. Já a terceira possui também marca de uso referente à gíria, com 0 sentido de pancada. Nessa acepção encontramos a presença de um exemplo, que objetiva oferecer um contexto ao consulente. Assim, de acordo com Krieger (2012), a contextualização representa um recurso positivo em dicionários escolares, considerando que por meio de um exemplo pode-se explicitar uma informação não compreendida pelo texto da definição. No entanto, se levarmos em consideração as primeiras definições do DDLP e o SJ, percebemos que o sentido principal retrata a fruta pitomba como árvore, não sendo relevante, pois não se trata da pitombeira, mas do fruto.

De acordo com essas informações, mesmo compreendendo que alguns dicionários possuem acepções insuficientes, isto é, que não expressam claramente 0 significado do verbete, podemos ter subsídios para criar estratégias pedagógicas para 0 ensino de língua materna, explorando as informações que estão implícitas, cabe ao professor incitar aos alunos sobre os fatores que são pertinentes sobre a língua, quais sejam: questões de regionalismo, sinonímia e antonímia, o contexto das definições, informações etimológicas, prosódicas, ortográficas, entre outros, que devem ser questionados durante 
os estudos com os dicionários. Tal estratégia poderá contribuir efetivamente com a construção crítica e reflexiva do aluno.

Como outro exemplo oriundo da análise, apresentamos 0 verbete relativo à entrada frevo:

- DEABL-(fre.vo) [ê] s.m.1.Dança carnavalesca típica de Pernambuco, caracterizada pelo ritmo sincopado e por movimentos acrobáticos dos participantes, vestidos com fantasias típicas, agitando sombrinhas coloridas. 2. 0 ritmo e a música dessa dança.

- AJ - fre.vo (ê) subst. masc. Brasileirismo Nordeste Dança carnavalesca de rua e salão, essencialmente rítmica, de coreografia individual e andamento rápido.

- CA - (fre.vo) [ê] sm. 1. Dança carnavalesca típica de Pernambuco, na qual os dançarinos seguram uma sombrinha aberta e movimentam pernas e braços rapidamente. 2. 0 ritmo musical que acompanha essa dança. [F.: De fervo, dev. de ferver, com metátese.]

- DDLP - <fre.vo> (Pron. [frêvo]) s.m. 1 Composição musical de origem brasileira, geralmente instrumental e com ritmo e compasso binário, com andamento bastante acelerado $\mathrm{e}$ agitado: 0 frevo é a música típica do carnaval de Pernambuco. 2. Dança que acompanha essa composição musical: Pedi a ela que me ensinasse a dançar o frevo.

- SJ - (fre.vo) (ê) sm. Bras. Folcl. Gênero musical e dança típicos do carnaval pernambucano, com ritmo acelerado e passos elaborados (Dá-se o nome de passo, fazer o passo, à maneira de se dançar o frevo.).

Todos os dicionários marcam foneticamente o fechamento da vogal "e" no verbete, indicando a pronúncia adequada. Observa-se que os dicionários não optam pelo símbolo fonético do alfabeto fonético internacional, mas por uma marcação mais simplificada, coadunada ao nível do consulente, isto é, alunos dos últimos anos do ensino fundamental.

0 DEABL apresenta duas acepções, a primeira como dança de determinada região, e a segunda como ritmo. Apesar de não haver marcas de uso, as acepções são claras, considerando as características elencadas. Já, em relação ao AJ, traz marcas de uso indicando regionalismo e dança, na sua única definição, aborda 0 frevo como dança.

0 CA apresenta duas acepções semelhantes às do DEABL. 0 diferencial consiste na indicação da derivação da palavra frevo, que vem de fervo. No DDLP, constam também duas acepções, mas acrescentadas de exemplos, Aliás, dos dicionários analisados, este é o único que apresenta exemplos para este verbete.

Com relação ao SJ, nota-se que traz apenas uma acepção como o AJ. 0 SJ, no entanto, elenca em uma mesma acepção dois significados, 0 de gênero musical e 0 de dança típica. As marcas de uso indicam brasileirismo e folclore. Apesar das peculiaridades, não encontramos nesse verbete grandes diferenças entre os dicionários, o que é visto positivamente à luz da lexicografia.

Analisamos também como esses dicionários caracterizam alguns verbetes que podem figurar palavras de baixo calão, pois para Zavaglia (2016, p. $10)$,

Considerando os estudos
sociolinguísticos, esse tipo de unidade
lexical é concebido como uma
variante popular, ou melhor, vulgar.
As variações linguísticas dividem-
se entre a norma culta e a norma
popular - a primeira é aquela de
maior prestígio social, isto é, a que
se impõe como marca dos falantes
com maior grau de escolaridade, e a
segunda é vulgar, ou seja, seu inverso.
Embora essa afirmação tenha grande
valia e seja pertinente, o prestígio
das variantes linguísticas depende
também do contexto em que são
empregadas.


Assim sendo, consideramos importante observar como os dicionários caracterizam esses verbetes, haja vista que os mesmos se fazem presentes, por vezes, no dialeto comum, e, mesmo considerados em seu sentido vulgar, devem ser explorados nos dicionários destinados às escolas. Vejamos, pois, o verbete quenga:

- $\quad \mathrm{DEABL}$ - Não possui acepção

- $\quad$ AJ - Não possui acepção

- $\quad$ CA - (quen.ga) sf. N.E. Vulg. Prostituta, meretriz [F.: Do quimb.]

- DDLP - <quen.ga> s.f 1 pejorativo Prostituta. 2 Vasilha feita com uma das metades da casca de um coco. ORIGEM É uma palavra de origem africana.

- $\quad$ SJ - (quen.ga) sf NE 1. Meretriz, prostituta; 2. Vasilha feita com a metade da casca de um coco; 3 . 0 conteúdo dessa vasilha. Var nas acep. 2 e 3 quengo.

Como podemos perceber o DEABL se mantém neutro quando a definição de quenga, bem como $0 \mathrm{AJ}$, considera essa neutralidade negativa, pois como dito anteriormente, 0 uso desse verbete pode se constituir no dialeto comum, mesmo que de maneira pejorativa. Por isso, é relevante a sua classificação.

Em relação ao $\mathrm{CA}$, por meio da marca de uso vulgar, traz apenas uma acepção, indicando significar prostituta, meretriz, e, mostra também a etnografia da palavra, ou seja, relativa à África.

Em oposição aos demais, tanto o DDLP e SJ figuram nos verbetes mais de um significado. A primeira acepção do DDLP marca 0 verbete como pejorativo indicando como prostituta, já na segunda, indica que se trata de uma vasilha, feita com uma das metades da casca do coco, também é exposto à origem da palavra, africana.

No SJ temos três acepções, a primeira define quenga como prostituta, na segunda refere-se à vasilha feita com uma das metades do coco, e na terceira, temos a definição de quenga como sendo 0 conteúdo dessa vasilha. Por fim, há uma indicação de "variação" para as acepções 2 e 3 indicando ser uma variável do verbete quengo. Vale salientar que tanto 0 CA como SJ utilizam a abreviatura NE, a qual designa a região Nordeste, logo compreendemos que tal verbete seja comum nessa região.

Em relação ao verbete bicha, vejamos as acepções:

- $\quad$ DEABL - (bi.cha) s.f. 1. fam. Nome comum à sanguessuga, à lombriga e aos vermes e répteis de forma comprida e sem pernas. 2 . fam. Verme intestinal; lombriga. S.m e f. 3. pej. Homossexual masculino.

- $\mathrm{AJ}$ - bi.cha subst. fem. Popular lombriga.

- $\quad$ CA - (bi.cha) sf. 1 bras. Lombriga. 2. Sanguessuga. 3. Lus. Fila. A2g.s2g. 4 Bras. Vulg. Pej. Homossexual masculino, homem efeminado. [At! Considerado depreciativo ou preconceituoso nesta acepção.] bi.chi.ce sf.

- DDLP - <bi.cha > s.f. pejorativo Homem afeminado.

- $\quad$ SJ - (bi.cha) sf 1. Bras. Lombriga; 2. Lus. fila; s2gên. 3. Bras. Vulg. Homossexual masculino.

No DEABL temos três acepções para bicha: a primeira, relacionada a vermes e répteis de forma comprida e sem pernas, na segunda há uma repetição, porém diferenciando pela característica do verme ser intestinal, o que consideramos repetitivo; na terceira, há um pejorativo, que se refere ao homossexual masculino.

No que diz respeito ao verbete no AJ, continuamos encontrando neutralidade, haja vista que o dicionário se propôs a defini-la apenas com uma significação, ou seja, como lombriga, sem levar em consideração o uso pejorativo.

Em contraposição, o CA define a partir de quatro acepções diferenciadas, a primeira com 
marca de uso referente ao Brasil, para designar como lombriga. A segunda acepção diz respeito à sanguessuga, e a terceira há uma marca de uso trazendo o lusitanismo, vislumbrando o significado pertinente a Portugal, isto é, bicha significa fila. E por fim, na quarta acepção temos três marcas de uso, referente à palavra brasileira, vulgar e pejorativa, que indica homossexual, homem afeminado. Ainda é interessante percebermos que existe 0 cuidado em explicar que nessa última acepção existe 0 caráter preconceituoso ou depreciativo.

Notamos que no DDLP temos apenas uma acepção para bicha, marcada como pejorativo, homem afeminado, nesse caso utiliza apenas a variante popular, ao contrário do AJ, que não traz essa variação, apesar de marcar a acepção como popular.

Em relação ao SJ, temos na primeira e na terceira acepção a marca de uso referente ao Brasil, na primeira com relação à lombriga, já na terceira indica para homossexual masculino, nessa acepção também há a marca de uso referente a vulgar. $\mathrm{Na}$ segunda acepção, assim como 0 CA, traz a marca de uso "lus." de lusitanismo, em consequência definindo como fila, nessa acepção o substantivo é considerado de dois gêneros.

A esse respeito, segundo Zavaglia (2016, p.12),

Quando se usam os ditos "palavrões", provocam-se, de imediato, duas reações diferentes na sociedade: uma de crítica porque infringe os padrões linguísticos e outra de curiosidade, visto que qualquer reação às regras sociais em vigor causa surpresa. Em geral, o léxico proibido é utilizado pelos falantes para expressar injúria, blasfêmia, agressão ou para exprimir um sentimento mais do que uma comunicação. Por isso, deixa de ser exclusivo de uma só classe. Esse tipo de emprego vocabular é visto como elemento de libertação para aliviar a tensão social, abarcando todos os níveis da comunidade.
Dessa forma, é necessário que esse tipo de léxico também seja explorado nos dicionários escolares, sem que haja censura ou neutralidade, para melhor atender aos seus consulentes.

Como vimos nas análises, que propositalmente incluímos dois verbetes considerados também pejorativo, podemos perceber que alguns dos dicionários do tipo 3 , ainda apresentam muita neutralidade em relação a esse léxico, 0 que impossibilita o seu estudo, em consequência, a sua prática pedagógica.

Portanto, quando aliado à prática pedagógica, 0 dicionário escolar pode exercer grandes contribuições para a aprendizagem de língua, pois exercer várias funções, agregando diversos gêneros textuais, e informações multifacetadas, assim, o dicionário age como facilitador da aquisição da língua.

\section{CONSIDERAÇÕES FINAIS}

Com 0 presente artigo, objetivamos propor reflexões acerca da Lexicografia Pedagógica, bem como ressaltar a importância do uso do dicionário em sala de aula. As escolas públicas dispõem de vários acervos que compõem o PNLD Dicionários, contudo, os professores não sabem como utilizáIos. Consequentemente, os alunos acabam perdendo a chance de utilizar um grande instrumento de apoio para aprendizagem da língua portuguesa.

Por meio da pesquisa realizada, foi possível constatar a diversidade e a complexidade apresentadas pelas obras que compõem o corpus. Esta heterogeneidade de informações pode ser aliados à prática docente por meio de atividades, considerando que, ao vislumbrar a formação de um verbete, vários fatores linguísticos e extralinguísticos podem ser abordados. Em outras palavras, há nos dicionários uma série de informações a respeito da língua, as quais precisam ser observadas e aplicadas na prática de ensino. Para tanto, é imprescindível que os professores de línguas tenham a consciência do valor pedagógico do dicionário, compreendendo além 
do aspecto estrutural, as várias funções que ele possui. Nesse sentido, vale reforçar a ideia da necessidade de inclusão da disciplina de Lexicografia Pedagógica nos cursos de letras, a julgar pela importância da formação do professor, cujo papel dentro da sala de aula consiste em conduzir seus alunos ao conhecimento da língua da melhor forma possivel, compreendendo o contexto lexicográfico, sabendo discernir as obras mais adequadas para serem trabalhadas, bem como avaliando seu papel pedagógico.

Assim, após um olhar científico sobre a constituição dos dicionários escolares do tipo 3 , pudemos constatar que mesmo tendo sido elaborados com 0 intuito pedagógico e avaliados pelo PNLD 2012, ainda há fatores que podem ser aprimorados.

\section{AGRADECIMENTO}

Agradecemos ao CNPq, pelo apoio à pesquisa por meio de uma bolsa de iniciação científica.

\section{REFERÊNCIAS}

AUROUX, S. A revolução tecnológica da gramatização. Campinas: Unicamp, 1992.

BECHARA, E. (Org.). Dicionário escolar da Academia Brasileira de Letras. 3. ed. São Paulo: Cia. Ed. Nacional, 2011.

BRASIL. Com direito à palavra: dicionários em sala de aula. Brasília: Ministério da Educação; Secretaria de Educação Básica, 2012.

FERREIRA, A. B. H. Aurélio Júnior: dicionário escolar da língua portuguesa. 2. ed. Curitiba: Positivo, 2011.

GEIGER, P. (Org.). Caldas Aulete: minidicionário contemporâneo da língua portuguesa. 3. ed. Rio de Janeiro: Lexikon, 2011.

KRIEGER, M. G. Dicionário em sala de aula: guia de estudos e exercícios. Rio de Janeiro: Lexikon, 2012.

KRIEGER, M. G. Políticas públicas e dicionários para escola: o Programa Nacional do Livro Didático e seu impacto sobre a lexicografia didática. Cadernos de tradução (UFSC), v. 18, p. 235-252, 2007.

PONTES, A.L. Dicionário para uso escolar: 0 que é como se lê. Fortaleza: EdUECE, 2009.

RAMOS, R. A. (Ed.). Dicionário didático de língua portuguesa. 2. ed. São Paulo: SM, 2011.

SANTIAGO, M. S. Análises contrastivas de microestruturas em dicionários escolares. Pesquisas em Discurso Pedagógico, n. 1, p. 1-14, 2012.

SANTIAGO, M. S. Critérios de avaliação de dicionários escolares de língua portuguesa no Programa Nacional do Livro Didático. In: LIMA, A. M. P.; DUARTE, A. L. M. et al. (Org.). Reflexões linguísticas e literárias. Fortaleza: HBM, 2015. p. 69-79.

SARAIVA, K. S. A.; OLIVEIRA, R. C. G. Saraiva jovem: dicionário da língua portuguesa ilustrado. São Paulo: Saraiva, 2010.

ZAVAGLIA, C. 0 "proibido" em dicionários. In: ALVES, I. M.; GANANÇA, J. H. L. (Org.). Os estudos lexicais em diferentes perspectivas. v. VI. São Paulo: FFLCH/USP, 2016. p. 9-18. 